\title{
MOTIVAÇÕES, HABILIDADES E COMPETÊNCIAS DO CONTROLLER NA PERCEPÇÃO DE ALUNOS QUE CURSAM PÓS-GRADUAÇÃO EM CONTROLADORIA
}

\author{
CONTROLLER'S MOTIVATIONS, SKILLS AND COMPETENCIES IN THE \\ PERCEPTION OF STUDENTS WHO COURSE POST-GRADUATE IN CONTROLLING
}

\author{
MARA VOGT \\ Doutoranda em Ciências Contábeis e Administração pela \\ Universidade Regional de Blumenau (FURB). Endereço: Rua Antonio \\ da Veiga, 140, Sala D-202 / Vitor Konder / Caixa Postal 1507 / 89012 - \\ 900 / Blumenau/SC / Brasil. \\ E-mail: maravogtcco@gmail.com
}

\section{LARISSA DEGENHART}

Doutoranda em Ciências Contábeis e Administração pela Universidade Regional de Blumenau (FURB). Endereço: Rua Antonio da Veiga, 140, Sala D-202 / Vitor Konder / Caixa Postal 1507 / 89012 900 / Blumenau/SC / Brasil.

E-mail: lari_ipo@hotmail.com

\section{CARLOS EDUARDO FACIN LAVARDA}

Doutor em Contabilidade pela Uninersitat de Valencia, Espanha. Professor do Programa de Pós-Graduação em Ciências Contábeis da Universidade Federal de Santa Catarina (UFSC). Endereço: Campus Reitor João David Ferreira Lima, s/n / Centro Socioeconômico / Trindade / 88040-900 | Florianópolis/SC / Brasil.

E-mail: elavarda@gmail.com

\section{RESUMO}

Este estudo objetivou analisar as motivações, habilidades e competências do controller na percepção de alunos que cursam pós-graduação em controladoria. Realizou-se uma pesquisa descritiva, de levantamento e com abordagem quantitativa. A população deste estudo foi definida por acessibilidade e compreendeu as Instituições de Ensino Superior de Santa Catarina que possuem pós-graduação em Controladoria, ou seja, 278 alunos. Já a amostra do estudo foi composta por 58 alunos que responderam devidamente ao questionário. Para analisar os dados, utilizou-se o método estatístico de correlação canônica por meio do software estatístico StatGraphics ${ }^{\circledR}$. Os resultados do estudo indicaram que quanto maior for a perspectiva de aumento salarial, maior será a visão ampla e crítica das operações e a capacidade de implementar novas ideias e projetos e menor será a responsabilidade por conhecimentos de finanças, contabilidade geral, de custos, habilidades de liderança e trabalho em equipe e, proatividade. Contudo, quanto menor for a perspectiva de melhorias na carreira e a satisfação profissional, maior será a visão ampla e crítica das operações e capacidade para implantação de novas ideias e projetos e menores serão as responsabilidades por conhecimentos de finanças, contabilidade geral, de custos, habilidades de liderança e trabalho em equipe e proatividade. 
Palavras-chave: Controladoria. Motivações. Habilidades e Competências. Controller.

\begin{abstract}
This study aimed to analyze the motivations, abilities and competences of the controller in the perception of students who study post-graduation in controller. A descriptive survey and a quantitative approach were carried out. The population of this study was defined by accessibility and comprised the Higher Education Institutions of Santa Catarina that have a post-graduate degree in Controllership, that is, 278 students. The sample of the study was composed of 58 students who answered the questionnaire duly. To analyze the data, the statistical method of canonical correlation was used by statistical software StatGraphics $\AA^{\circledR}$. The results of the study indicated that the greater the prospect of a salary increase, the greater the broad and critical view of operations and the ability to implement new ideas and projects, and the lower the responsibility for knowledge of finance, general accounting, costs, skills Leadership and teamwork, and proactivity. However, the lower the prospect of career advancement and job satisfaction, the greater the critical and broad vision of operations and the ability to implement new ideas and projects, and the smaller the responsibilities for financial literacy, general accounting, cost, Leadership skills and teamwork and proactivity.
\end{abstract}

Keywords: Controllership. Motivations. Skills and Competencies. Controller.

\title{
1 INTRODUÇÃO
}

A demanda por profissionais de controladoria aumentou consideravelmente a partir dos anos 60. Esse aumento deve-se à importância do processo de industrialização que o Brasil passou durante essa década (Siqueira \& Soltelinho, 2001). Entretanto, o surgimento da controladoria contemporânea iniciou no século $X X$, com a proliferação das empresas multinacionais. A partir de então, exerce papel fundamental nas organizações. Apoia gestores nas fases de planejamento, execução e controle. O suporte que a controladoria dá ao processo de gestão implica em um sistema de informações que permite integrar vários níveis. No Brasil, o profissional que exerce as funções de controladoria é denominado controller. Entretanto, ao longo dos anos e em diversos países, foram várias as atribuições dadas a esse profissional (Oro, Beuren, \& Carpes, 2013). Desse modo, diversas têm sido as funções atribuídas ao profissional de controladoria. É relevante para a evolução das organizações e sua estrutura organizacional (operacional, gerencial e estratégico), a diversidade e a complexidade das competências designadas a esses profissionais (Araújo, Souto, \& Azevedo, 2016).

Por outro lado, deve-se levar em consideração que as empresas carecem cada vez mais de planejamento, controle e gestão de suas atividades, tarefas, bem como funções, em decorrência da competitividade que, de modo geral, é conferida ao setor de controladoria e até mesmo ao profissional controller. Isso ocorre, uma vez que o controller é designado a inteirar e coordenar várias áreas da empresa. Desse modo, a valorização dessa profissão resulta da necessidade das organizações prepararem o planejamento estratégico e controlarem o desenvolvimento das atividades (Gomes, Souza, \& Lunkes, 2014). Nesse sentido, a necessidade de controle nas empresas modernas e o fornecimento de informações de contabilidade gerencial é uma das principais tarefas dos profissionais de controladoria. Além disso, a maioria das empresas utiliza informações contábeis para fins de tomada de decisão e controle (Weissenberger \& Angelkort, 2011).

Para Oro et al. (2013), o profissional de controladoria demanda competências e habilidades gerenciais que são necessárias para a gestão de negócios. Independente do nível organizacional, ou seja, operacional, gerencial ou estratégico, sua função será gerencial. No que se refere às habilidades gerenciais, estas estão relacionadas ao comportamento e, as competências são imprescindíveis para a execução de determinado cargo.

Diversos fatores podem influenciar na atuação do controller. Duque (2011) cita o porte e a origem do capital. Para o autor, esse profissional de controladoria deve adaptar tanto suas habilidades quanto suas competências ao objetivo da organização. Isso se deve também à 
dinâmica da economia que está sob um novo cenário, demonstrando que as empresas estão cada vez mais competitivas. Necessitam de um profissional que auxilie da melhor forma a gestão.

Conforme Oro et al. (2013), o controller se destaca como o responsável pelo gerenciamento das informações, seja qual for a etapa do processo de gestão. Para tanto, deve estar preparado para compreender e direcionar as ações próprias e da organização. Além disso, os autores destacam que a formação de um profissional, indiferente a área, é marcada pela sólida formação acadêmica e continuada.

Mesmo que ao longo dos anos a relevância dos controllers tenha se consolidado há pouca literatura que auxilie na compreensão e clareza sobre as funções e competências atribuídas a esses profissionais (Araújo et al. 2016). Além disso, encontra-se a lacuna para o desenvolvimento desta pesquisa, pois há algumas divergências da prática dos profissionais que são formados na área de controladoria, com o que realmente os alunos aprendem na teoria nas Instituições de Ensino Superior. Esses alunos estão cursando pós-graduação com o intuito de buscar uma profissionalização específica, no caso a controladoria, para melhorar, dessa forma, suas habilidades e competências para com o tema e, sobretudo, aumentar sua motivação para trabalhar nessa área da contabilidade.

Diversos estudos buscaram analisar a temática analisada na presente pesquisa, tais como, Siqueira e Soltelinho (2001), Martin (2002), Calijuri, Santos e Santos (2005), Santos, Castellano, Bonacim e Silva (2005), Amaral e Rodrigues (2006), Lunkes, Schnorrenberger, Gasparetto e Vicente (2009), Machado, Lunkes, Petri e Rosa (2010), Duque (2011), Lunkes, Schnorrenberger e Rosa (2013), Oro et al. (2013), Ferrari, Cunha, Lunkes e Borgert (2013), Araújo et al. (2014), Gomes et al. (2014), Dal Vesco, Daniel e Tarifa (2014) e Pletsch, Silva e Lavarda (2016), estudos esses que possibilitam dar suporte ao problema de pesquisa. No entanto, não foram localizados estudos com o intuito de analisar o contexto desta pesquisa em pós-graduações na área de Controladoria. Apresenta-se assim, o diferencial e uma oportunidade para a investigação dessa temática relevante no contexto contábil.

Percebe-se que as competências e habilidades necessárias para a realização de uma tarefa devem ser compreendidas e levadas em consideração, principalmente quando se trata dessa profissão que ainda encontra-se em desenvolvimento (Duque, 2011). Além disso, tendo em vista a importância desse profissional para a área contábil e a escassez de pesquisas, no que se refere a alunos de pós-graduação em controladoria, o estudo busca responder à seguinte questão: quais as motivações, habilidades e competências do controller na percepção de alunos que cursam pós-graduação em controladoria? Dessa forma, o objetivo desta pesquisa é analisar as motivações, habilidades e competências do controller na percepção de alunos que cursam pós-graduação em controladoria.

É importante que sejam observadas as motivações, bem como as habilidades e competências dos controllers, pois a controladoria está crescendo cada vez mais e, a partir do momento em que forem levadas em consideração essas informações, consequentemente os profissionais trarão melhores resultados para a organização. Vale ressaltar que, conforme Duque (2011), no momento que as instituições souberem o que motiva seus acadêmicos, poderão preparar os profissionais para que não atendam somente aos requisitos técnicos, mas sim, para que tenham cada vez mais habilidades e competências para auxiliar a gestão. Até por que, a organização somente conseguirá contratar o profissional que procura, se souber o perfil que atenda sua necessidade.

Mesmo que as profissões relacionadas à área contábil tenham passado por significativo avanço no Brasil, as funções do controller ainda não estão bem definidas dentro das organizações. Contudo, para que seja reconhecido, é preciso que esse profissional exerça influência na organização para conduzir gestores pelo melhor caminho. Sendo assim, é imprescindível que o controller tenha suas funções bem definidas (Dal Vesco et al., 2014). Justifica-se ainda, de acordo com Oro et al. (2013), que sugerem analisar a percepção dos alunos sobre as habilidades e competências requeridas pelo mercado de trabalho, tendo em vista a constatação desses profissionais que atuam na controladoria.

Justifica-se, também, na visão de Baruch e Lemming (2001), pois, um curso de pósgraduação adiciona valor aos seus participantes, proporciona-Ihes capacidades e competências importantes para o desenvolvimento da carreira profissional. As razões para a 
realização desse curso é melhorar as perspectivas na carreira, por meio da obtenção de conhecimentos de gestão e, sobretudo, para o sucesso na vida profissional. Além disso, o ensino nos cursos de pós-graduação tem evoluído de forma acentuada, trazendo benefícios aos alunos e às empresas. A grande parte da procura se concentra nos Master of Business Administration (MBA), essa que foi uma criação norte-americana do início do século passado e que se expandiu para praticamente todo o mundo (Frezatti \& Kassai, 2003).O tema elucidado é relevante. Ao identificar as habilidades e competências requisitadas pelo atual mercado, é possível trabalhar para desenvolvê-las, visando ao aperfeiçoamento profissional dos controllers, bem como à aprendizagem continuada, essencial nos dias contemporâneos. Em relação às instituições que ofertam pós-graduação, as mesmas poderão utilizar os resultados com vistas a ajustar seus cursos frente às demandas do mercado.

Este estudo contribui para uma melhor formação profissional na área, a partir da análise das motivações, habilidades e competências mencionadas pelos alunos, comparado ao perfil esperado pelo mercado de trabalho. Além disso, as contribuições podem ser teóricas e práticas, tanto para a academia quanto para a empresa, levando em consideração a percepção dos discentes da pós-graduação em controladoria.

\section{REFERENCIAL TEÓRICO}

No referencial teórico, apresenta-se inicialmente a controladoria, conceitos e funções. $\mathrm{Na}$ sequência, descreve-se especificamente sobre as funções do controller. Além disso, evidenciam-se os estudos anteriores, que possibilitam embasar a presente pesquisa.

\subsection{Controladoria}

A importância da controladoria nas empresas vem crescendo nos últimos anos. O mercado deixou de buscar e contratar profissionais que se limitavam a transcrever informações e passou a procurar profissionais mais dinâmicos, capazes de gerar informações úteis e relevantes para ampliar o suporte à tomada de decisões empresariais (Santos et al., 2005). Da mesma forma, a área da controladoria passou por diversas mudanças nos últimos anos. Evoluiu da contabilidade de custos para a contabilidade gerencial e, por fim, para a gestão estratégica de custos. Desse modo, a controladoria possibilita que a administração adapte as empresas frente às mudanças do ambiente, por meio do processo de planejamento (Bencová \& Kalavská, 2009).

No ambiente moderno dos negócios, a contabilidade gerencial, que toma por base um modelo exclusivamente financeiro, não possibilita o suporte adequado à gestão da empresa no que tange à tomada de decisões. Para tanto, o modelo financeiro necessita incorporar novas dimensões, provindas da controladoria, pois, quando trabalham juntos formam um quadro geral de avaliação do desempenho, que não dá apenas explicações referentes ao estado atual da empresa, mas, sim, permite projeções, bem como simulações dos cenários futuros (Martin, 2002). Nesse sentido, Oro et al. (2013) salientam que a partir do momento que a contabilidade se adapta a esse novo ambiente é que evolui para o conceito denominado controladoria.

De acordo com Borinelli (2006, p. 105), "controladoria é um conjunto de conhecimentos que se constituem em bases teóricas e conceituais de ordens operacional, econômica, financeira e patrimonial, relativas ao controle do processo de gestão organizacional". Destaca, ainda, que a controladoria é responsável pelo controle do processo de gestão, geração e até mesmo pelo fornecimento de informações operacionais, econômicas, financeiras e patrimoniais, para a tomada de decisões.

Como missão, a controladoria busca dar suporte à gestão das empresas, com vistas a assegurar que essa atinja os objetivos, ou seja, busca otimizar os resultados econômicos, interagindo com as demais áreas. Desse modo, a controladoria tem como objetivos: promover a eficácia organizacional, viabilizar a gestão econômica e promover a integração das áreas das empresas (Borges, Parisi, \& Gil, 2005).

Nesse sentido, a controladoria detem informações em âmbito global das empresas e contribui na identificação e monitoramento dos riscos. Além disso, visa a proporcionar aos gestores instrumentos que permitem uma visão geral das aplicações de recursos, com o intuito 
de verificar como as metas serão alcançadas e, assim, tomar decisões (Guimarães, Parisi, Pereira, \& Weffort, 2009).

No entanto, a controladoria é uma área de estudos que carece de definições claras, bem como de conceituações, essas que incluem um conjunto básico de funções. Nesse sentido, o desenvolvimento da controladoria aconteceu a partir dos preceitos da contabilidade, visando a uma ampla função de suporte internacional, controle interno, planejamento tributário, participação na elaboração do orçamento. Passa, dessa forma, a atuar também na formulação de estratégias. Deixa de ser apenas o controller um profissional compilador de dados, para ser um gestor da informação voltado ao alinhamento estratégico das empresas (Lunkes, Gasparetto, \& Schnorrenberger, 2010; Lunkes, Machada, Rosa, \& Telles, 2011).

Segundo Oro et al. (2013), a controladoria é uma unidade administrativa que possui a missão de apoiar o processo de gestão da empresa. Para cumprir suas atribuições utiliza-se de diversas áreas do conhecimento humano. Desse modo, a empresa deverá contar com um profissional com habilidades e competências, para gerenciar a informação, de forma a responder aos desafios da organização.

A controladoria é responsável por estabelecer a base teórica e conceitual necessária para a construção, bem como para a manutenção dos sistemas de informações e modelo de gestão econômica, que atenda adequadamente às necessidades de informação dos administradores das empresas e, ainda, que auxilie no processo de tomada de decisão (Amaral \& Rodrigues, 2006).

Frente às constantes mudanças na economia mundial, o mercado exerce maior influência, com consequências para as empresas, essas que necessitam passar por processos de adaptação nos seus sistemas de informação com vistas à manutenção da competitividade. Diante disso, a controladoria busca coordenar os sistemas de gestão e atuar nos pontos vitais das empresas (Richartz, Krüger, Lunkes, \& Borgert, 2012). Contudo, a ascensão da controladoria resultou na busca por profissionais qualificados e que atendam ao perfil que é requisitado pelo mercado de trabalho. Diante disso, os cursos de pós-graduação passaram a ser mais procurados, com o intuito de desenvolver habilidades e competências necessárias para o desempenho da função de controller, essa que se baseia em diversificadas áreas do conhecimento.

\subsection{Funções, Habilidades e Competências do Controller}

A definição das funções é considerada um dos pontos fundamentais nos estudos relacionados à controladoria. Nesse sentido, as funções têm por objetivo orientar a atuação de determinada área do conhecimento. Contudo, há dificuldades nesse aspecto, em decorrência dos conceitos voltados ao tema, que por vezes são confusos e contraditórios na literatura (Lunkes et al., 2011; Lunkes et al. 2013). De acordo com Granlund e Taipaleenmaki (2005), a administração espera que os controllers desenvolvam ativamente os processos de finanças, controle e sistemas de informações das empresas.

Nesse sentido, as funções do controller podem variar de acordo com o tamanho da empresa e a quantidade de gestores nessa mesma função. Quanto menos gestores, mais funções o mesmo terá (Duque, 2011). Da mesma forma, Guimarães et al. (2009) e Oro et al. (2013) salientam que se deve levar em consideração que a função do controller pode mudar de uma empresa para a outra, de acordo com o porte empresarial e estrutura organizacional.

Sendo assim, os profissionais de controladoria que desejam se adequar ao perfil a que as empresas esperam, para aumentar seu potencial e desempenho, devem focar na multidisciplinaridade. O controller deve exercer as funções de planejamento, controle, orçamento, custos, análise financeira e contábil, saber trabalhar em equipe, ter liderança e visão global, ser proativo, ter visão empresarial e boa comunicação para melhorar o desempenho do próprio profissional de controladoria (Duque, 2011).

Os controllers são responsáveis por uma ampla gama de funções e sua experiência crescente pode alargar as tarefas que lhe são atribuídas. Para tanto, a natureza das tarefas do controller torna claro que suas interações com a área gerencial desempenham papel importante na análise das empresas (Weber, 2011). Da mesma forma, Dal Vesco et al. (2014) salientam que, dentre outras funções, esse profissional é responsável por coordenar pessoas 
para o alcance dos objetivos, ou seja, pela liderança. Para tanto, é o controller que deve motivar os demais colaboradores e orientá-los para o melhor caminho, para que se sintam satisfeitos, acompanhar e supervisionar os setores, desempenhar funções técnicas, operacionais e gerenciais. Além disso, os autores ressaltam que não basta apenas planejar e executar, é preciso controlar os processos de forma sutil, para que os objetivos sejam alcançados. Assim, cabe aos controllers o papel de orientar os gestores para a tomada de decisão (Dal Vesco et al., 2014).

Lunkes et al. (2009) destacam que a controladoria exerce um papel central no processo de gestão e uma ampla função para o suporte informacional, planejamento tributário, controle interno, elaboração do orçamento, formulação das estratégias. Dessa forma, o controller passa a ser o responsável por esse processo. São três as abordagens relacionadas às funções básicas da controladoria: gestão operacional que envolve o planejamento, elaboração de relatórios e interpretação, avaliação e deliberação, administração de impostos, elaboração de relatórios e órgãos reguladores e públicos, proteção do patrimônio, e, avaliações da economia política.

A segunda abordagem refere-se à gestão econômica. Tem por função subsidiar o processo de gestão, apoiar a avaliação de desempenho e a avaliação de resultado, gerir o sistema de informações, atender aos agentes de mercado. Além disso, os controllers que atuam na gestão estratégica têm a função de planejamento, sistema de informações, controle, gestão de pessoas e organizacional (Lunkes et al., 2009).

No que diz respeito às funções empíricas do controller, destaca-se a contábil, de controle, administração de impostos, interpretação e elaboração de relatórios, planejamento e controle interno. Já em relação às funções consolidadas, o controller é responsável pelo planejamento, controle, área contábil e elaboração de relatórios e sua devida interpretação. Por fim, as funções abordadas na literatura abrangem o controle, planejamento, sistema de informações contábil e elaboração e interpretação de relatórios (Lunkes et al., 2013). Diante das funções supracitadas, destaca-se que são diversas as habilidades, competências e motivações dos controllers frente às empresas. Desse modo, em relação às habilidades denota-se que, conforme as pessoas sobem de cargo em uma organização, as necessidades também acabam sendo outras e, consequentemente, as habilidades se alteram. Para tanto, é preciso uma grande habilidade técnica, principalmente no início de carreira dos controllers (Duque, 2011).

Nesse sentido, as empresas contemporâneas têm experimentado pressões competitivas. São forçadas a criar mecanismos para se diferenciar e incrementar a competitividade. Diante disso, a controladoria passa a exercer um papel fundamental nesse processo de gestão, visto que possui como funções dar suporte informacional, controle interno, planejamento tributário, elaboração de orçamentos, participação na formulação de estratégias. Assim, para que o controller consiga atender às suas demandas, necessita contar com um conjunto de competências técnicas e pessoais (Machado et al., 2010).

As competências do controller são consideradas um dos pontos fundamentais para qualquer estudo na área de controladoria. Contudo, tem-se encontrado dificuldades para identificar um conjunto básico de competências pessoais e profissionais na literatura (Machado et al., 2010). Em relação à competência, Duque (2011) salienta que a palavra tem origem do latim competentia e refere-se ao indivíduo que é capaz de analisar e resolver determinado assunto, com capacidade, habilidade, aptidão e, ainda, idoneidade. Exige-se um conjunto de competências do profissional que atua na controladoria, para que consiga atender às demandas (Oro et al., 2013).

De acordo com Simãozinho (2012), os profissionais de controladoria passaram a ter um papel essencial na gestão dos negócios das empresas, visto que essa área requer inovações em suas práticas. Isso tendo em vista um melhor desenvolvimento da sua capacidade de gerenciar as informações estratégicas e operacionais, e, assim, contribuir para a competitividade das empresas e apoiar a tomada de decisão das partes interessadas. $\mathrm{O}$ autor ainda destaca que os controllers são responsáveis por prover informações que suportem a tomada de decisão, pelo planejamento, bem como pela avaliação do desempenho econômicofinanceiro e operacional e, ainda, serve como base para a avaliação e compensação dos gestores. 
Além disso, o controller deve conhecer de forma ampla as atividades das empresas, de modo que consiga visualizar o desempenho e efetuar previsões futuras. Denota-se, então, que o controller não é responsável por uma área, mas sim possui a função de verificar as informações das empresas para os gestores tomarem as melhores decisões (Richartz et al., 2012).

\subsection{Estudos anteriores}

A preocupação em verificar a percepção de alunos de Pós-Graduação em Controladoria sobre as habilidades e competências desenvolvidas no que se refere às funções do controller foi objeto de alguns estudos de diferentes ambientes e autores. Contudo, dentre os estudos evidenciados, poucos verificaram esse tema em cursos de pós-graduação.

No estudo de Siqueira e Soltelinho (2001) os autores objetivaram avaliar a evolução do controller no Brasil baseado nos anúncios publicados na seção de classificados. Selecionaram diversos anos com base nos anúncios publicados no caderno de Classificados de Domingo do Jornal do Brasil. Consideraram uma definição ampla do termo controladoria, não selecionando apenas os anúncios que procurassem controllers. Os resultados apontaram que a avaliação econômica é uma função necessária para o desempenho do papel de controller. Além disso, o interesse foi maior por profissionais com formação em ciências contábeis, economia e, em menor grau, em administração. O mercado busca profissionais com experiência, profundos conhecedores em informática, que tenham domínio de uma ou mais línguas estrangeiras, sejam habilitados a trabalhar sob pressão e em equipe, sejam comunicativos e tenham capacidade de liderar.

O estudo de Martin (2002) objetivou analisar a evolução necessária da contabilidade à controladoria, por meio de um estudo qualitativo e descritivo. Após a análise realizada dessa evolução, concluiu que o controller necessita ser por excelência um profissional generalista, com capacidade para entender profundamente sua empresa, bem como seu ramo de negócios. Além disso, precisa entender, manejar e criticar métodos, instrumentos de pesquisa, análise e formas de atuação de um grande número de especialistas funcionais que atuam na organização.

Calijuri et al. (2005) objetivaram mostrar o papel do controller por meio de uma pesquisa exploratória. Dessa forma, aplicaram questionários aos profissionais que ocupavam as funções de controller. Os resultados apontam que os controllers indicaram que as habilidades mais importantes para o desempenho do seu trabalho são: liderança, flexibilidade para mudanças, facilidade de relacionamento interpessoal, capacidade para implantação de novas ideias e projetos, iniciativa, conhecimento de finanças e ainda, a proatividade. Entre os cursos mais procurados por esses profissionais estão os de Ciências Contábeis e Administração de Empresas. Além disso, a maioria, isto é, 19 alunos realizaram a pós-graduação em MBA e 14 cursaram especialização em Controladoria.

Santos et al. (2005) desenvolveram um estudo com base nas 500 maiores empresas do Brasil, com o intuito de delinear as principais funções, atribuições, responsabilidades, habilidades e atitudes do perfil do controller. Os resultados indicaram que as empresas brasileiras analisadas buscam um perfil do controller com experiência entre 3 a 10 anos, com MBA ou especialização, formação em ciências contábeis, administração e economia, iniciativa, visão econômica, liderança e ética. Quanto às principais funções estão: implantação e supervisão do plano contábil, compilação dos custos de produção e distribuição, preparação, apresentação e supervisão de assuntos referentes a impostos, preparação e interpretação das estatísticas e relatórios para decisão administrativa, foco no orçamento global da empresa e conhecimento na área fiscal, tributária e contábil.

O estudo desenvolvido por Amaral e Rodrigues (2006) objetivou demonstrar as funções desempenhadas pelos controllers e o ensino da disciplina de controladoria nos programas de pós-graduação em nível de especialização em Ciências Contábeis, bem como o profissional atuante no mercado de trabalho. Elaboraram um questionário e enviaram aos coordenadores e/ou professores que ministram a disciplina de controladoria e realizaram entrevistas com profissionais que estão exercendo a função de controller nas empresas. Em relação ao papel do controller na visão dos professores, em primeiro lugar encontra-se a função de orçamento, 
controle financeiro, contabilidade e custos. Já para os profissionais, as principais funções do controller seriam de informação, motivação, coordenação, avaliação, planejamento e acompanhamento e, ainda, a de funcionário estratégico no fornecimento de visão crítica. Assim, os resultados apontam que o curso de Ciências Contábeis pode tornar o controller muito técnico e sem visão de negócios.

A pesquisa de Lunkes et al. (2009) objetivou identificar um conjunto de funções da controladoria em manuais e obras de referência nos Estados Unidos, Alemanha e Brasil. O resultado da pesquisa, comum aos três países, foram as funções de: planejamento (87\%); controle (83\%); elaborar e interpretar relatórios (47\%); e alimentar o sistema de informação $(43 \%)$. Os resultados demonstraram que as funções mais citadas são as de planejamento (87\%) e controle (83\%), que o papel do controller possui um caráter proativo na organização. Evidencia também que a controladoria, no seu desenvolvimento, tem incorporado funções mais amplas e sistêmicas. Esse resultado revela que grande parte das preocupações da controladoria devem estar mais voltadas para o futuro da organização, ou seja, espera-se que o controller tenha uma postura proativa em relação à organização, e não apenas informativa.

Machado et al. (2010) tiveram por objetivo identificar as competências do controller nas 100 maiores empresas do Estado de Santa Catarina. Os achados revelaram que as competências pessoais dos controllers estão mais relacionadas a características como trabalhar sobre pressão, ética, flexibilidade para mudanças, honestidade e integridade, iniciativa e liderança, entre outras. Já as competências profissionais estão relacionadas a características como visão estratégica e de processos, raciocínio lógico, planejamento e organização.

Diante do objetivo de analisar o atual perfil profissional de competências e habilidades exigidas pelas empresas contratantes para a função de controller e investigar se o perfil tem associação ao porte da empresa, à origem de capital, à hierarquia do cargo, formação acadêmica e salário ofertado pelo atual mercado de trabalho, Duque (2011) encontrou resultados que revelaram associação entre o perfil comportamental e o porte da empresa e a origem de capital, entre o perfil técnico e a hierarquia do cargo e também entre os benefícios oferecidos e o porte da empresa.

A pesquisa desenvolvida por Lunkes et al. (2013) objetivou identificar e analisar as principais funções da controladoria em estudos empíricos e em obras e manuais de referência. Entre as funções consolidadas em termos de obras e manuais e estudos empíricos destaca-se o planejamento, o controle, o contábil e a elaboração de relatórios e interpretação.

O estudo de Oro et al. (2013) analisou a aderência entre as competências e habilidades requeridas pelo mercado nacional na contratação do profissional de controladoria e a proposição para sua formação acadêmica na percepção de docentes da disciplina de controladoria. Os resultados relacionam as competências e habilidades requeridas pelo mercado nacional na contratação do profissional de controladoria e a proposição para sua formação acadêmica na percepção de docentes da disciplina de controladoria. Os autores concluíram que existe certa aderência entre o perfil desejado pelo mercado de trabalho e a proposição para a formação acadêmica do controller.

A partir do objetivo de identificar as funções e atribuições do controller solicitadas pelas empresas brasileiras no processo de recrutamento no mercado de trabalho nacional, Ferrari et al. (2013) revelaram que as funções solicitadas que mais se destacam são o gerenciamento da contabilidade, o controle fiscal e tributário, o planejamento estratégico e os relatórios gerenciais. Em relação às competências, as que mais se destacam são: visão global de mercado, dinamismo, liderança, proatividade e conhecimento em IFRS/ERP. Além disso, a solicitação por profissionais com formação acadêmica em contabilidade tem diminuído, e se passou a exigir o domínio de uma segunda língua. Pode-se concluir que o mercado está demandando controllers capazes de gerir as informações das organizações e que se destaquem pelos conhecimentos técnicos e interpessoais.

O estudo de Araújo et al. (2014) teve por objetivo identificar as habilidades e competências desenvolvidas em cursos de pós-graduação (lato senso) com ênfase em controladoria, relacionadas com o perfil contemplado na literatura para o controller. Os dados foram coletados por meio de um questionário aplicado aos alunos do curso de pós-graduação em controladoria nas IES da cidade de João Pessoa - PB. Os resultados do estudo revelam 
que em relação às competências mais desenvolvidas se destacam: habilidades específicas do controller, ou seja, financeiras, de avaliação econômica, habilidades associadas à contabilidade, procedimentos de auditoria, mensuração de riscos organizacionais, sistemas de informação contábil, consultoria e procedimentos de controle interno e, ainda, planejamento estratégico. Afirmam, ainda, que um curso de pós-graduação pode adicionar valor aos alunos, tornando-os mais preparados para enfrentar o mercado de trabalho.

A pesquisa de Gomes et al. (2014) teve por objetivo identificar o perfil do profissional da controladoria solicitado pelas empresas brasileiras. Os autores concluíram que o perfil solicitado para os profissionais da controladoria está mudando com o passar dos anos. Está deixando de ser uma função essencialmente contábil, para ser um profissional estratégico, participante da gestão de forma sistemática, com liderança, proatividade e capacidade analítica.

Dal Vesco et al. (2014) desenvolveram o estudo no segmento de Cooperativas Agropecuárias do Estado do Paraná, com vistas a identificar o perfil dos controllers no que tange às funções. Os resultados revelaram que $85,7 \%$ dos controllers possuíam formação superior no curso de ciências contábeis, os demais em administração e outros cursos. 88,9\% da amostra cursaram pós-graduação em MBA (88,9\%), 42,9\% ocupam o cargo de gerência, $23,8 \%$ o de diretoria e $19 \%$ o de supervisão. $95 \%$ dos controllers exercem a função de gestão de custos, $90 \%$ a de planejamento e controle orçamentário, $90 \%$ de elaboração de relatórios gerenciais e $86 \%$ a de coordenação de fechamentos contábeis mensais. No que tange às habilidades, os resultados demonstraram que $100 \%$ dos controllers têm habilidade em liderança e cooperação, $86 \%$ habilidades em iniciativa e flexibilidade para mudanças, visão de futuro, persistência e persuasão e habilidades de relacionamento interpessoal e implantação de novas ideias/projetos, $81 \%$ têm conhecimento em finanças e domínio de língua estrangeira e $76 \%$ atitudes pautadas em ética.

O estudo desenvolvido por Pletsch et al. (2016) buscou identificar como são abordados, nos cursos de ciências contábeis, de universidades sulistas brasileiras, os conteúdos da disciplina de controladoria e as funções do controller no mercado de trabalho. Os resultados evidenciaram que as exigências do mercado de trabalho para o exercício da profissão contábil encontram-se situadas no processo contábil e financeiro das empresas e que a disciplina de controladoria atende a todas as exigências do mercado, além de ser a mais abrangente. As funções de controladoria: sistema de informação, planejamento e controle, destacaram-se no presente estudo e nos estudos relacionados.

\section{PROCEDIMENTOS METODOLÓGICOS}

Com o intuito de atender ao objetivo proposto, de analisar a relação entre as motivações e as habilidades e competências do controller na percepção de alunos de pósgraduação em controladoria, realizou-se uma pesquisa descritiva, de levantamento e com abordagem quantitativa.

O questionário foi elaborado a partir da literatura evidenciada no referencial teórico e adaptou-se o instrumento utilizado por Araújo et al. (2014) com perguntas fechadas em escala do tipo Likert de 1 a 5 e encontra-se dividido em quatro partes: Parte I: Perfil dos Respondentes, Parte II: Motivações para buscar uma pós-graduação em controladoria, Parte III: Habilidades e competências desenvolvidas na pós-graduação e Parte IV: Contribuição da pós-graduação na relação entre o conhecimento teórico e a prática. Destaca-se que esse questionário foi submetido a um teste de confiabilidade realizado por três professores doutorandos do curso de Ciências Contábeis, que verificaram o conteúdo das questões. Após a verificação, o questionário foi ajustado de acordo com as considerações.

Antes de encaminhar o questionário foi realizado contato com os responsáveis pelos cursos de pós-graduação em Controladoria das IES da amostra, ressaltando a importância deste estudo e justificando a necessidade de que os questionários retornassem respondidos. Assim, encaminhou-se o link dos questionários que foram elaborados no Google Docs nos meses de setembro e outubro de 2015, solicitando que enviassem para os respectivos alunos. 
A população deste estudo foi selecionada por acessibilidade e compreendeu as Instituições de Ensino Superior de Santa Catarina que possuem curso de pós-graduação em Controladoria. Vale ressaltar que, são diversas as nomenclaturas para pós-graduação na área gerencial, tais como, gestão estratégica das empresas, contabilidade de custos, entre outras. Contudo, optou-se por analisar as pós-graduações que apresentavam a nomenclatura de "Controladoria", o que permite maior comparabilidade. Entretanto, destaca-se que mesmo havendo idêntica nomenclatura, pode haver diferenças na matriz curricular, ementa, formação dos professores, dentre outros fatores, que são considerados limitações para o desenvolvimento deste estudo.

Por meio da Tabela 1 apresentam-se as Instituições de Ensino Superior, sua respectiva cidade, bem como a quantidade de alunos para os quais foi encaminhado o questionário, constituindo a população da presente pesquisa.

Tabela 1

\section{População da pesquisa}

\begin{tabular}{|c|c|c|}
\hline Instituição de Ensino Superior & Cidade & Alunos \\
\hline Centro Universitário Barriga Verde - UNIBAVI & Orleans & 23 \\
\hline $\begin{array}{l}\text { Centro Universitário para o Desenvolvimento do Alto Vale do Itajaí - } \\
\text { UNIDAVI }\end{array}$ & Rio do Sul & 35 \\
\hline Faculdade Empresarial de Chapecó - UCEFF & Chapecó & 35 \\
\hline Universidade Comunitária Regional de Chapecó - UNOCHAPECÓ & Chapecó & 31 \\
\hline Universidade da Região de Joinville - UNIVILLE & $\begin{array}{l}\text { São Bento do } \\
\text { Sul }\end{array}$ & 24 \\
\hline Universidade do Oeste de Santa Catarina - UNOESC & Chapecó & 45 \\
\hline Universidade do Oeste de Santa Catarina - UNOESC & Joaçaba & 21 \\
\hline SEI FAI Faculdades/ Pólo UCEFF & Itapiranga & 54 \\
\hline Serviço Nacional de Aprendizagem Comercial - SENAC & Concórdia & 10 \\
\hline
\end{tabular}

Nota. Fonte: Dados da pesquisa (2014).

Nota-se, a partir do Tabela 1, que a população compreendeu 278 alunos de pósgraduação em Controladoria do Estado de Santa Catarina. Já a amostra do estudo foi composta por 58 alunos que responderam devidamente ao questionário.

No Tabela 2 apresenta-se a codificação das motivações e habilidades e competências utilizadas no instrumento de pesquisa, para facilitar o entendimento na análise dos resultados.

Tabela 2

Codificação das motivações e habilidades e competências do instrumento de pesquisa

\begin{tabular}{|c|c|c|}
\hline Grupos & Cod. & Questões/variáveis \\
\hline \multirow{9}{*}{$\begin{array}{l}\text { Motivações para } \\
\text { cursar uma pós- } \\
\text { graduação em } \\
\text { controladoria }\end{array}$} & M1 & Melhoria das habilidades gerenciais \\
\hline & M2 & Perspectiva de melhorias na carreira \\
\hline & M3 & Perspectiva de aumento salarial \\
\hline & M4 & Satisfação profissional \\
\hline & M5 & Satisfação pessoal \\
\hline & M6 & Atualização profissional (capacitação) \\
\hline & M7 & Aquisição de novas competências \\
\hline & M8 & Melhoria na autoestima \\
\hline & M9 & Mudança de carreira \\
\hline \multirow{10}{*}{$\begin{array}{c}\text { Habilidades e } \\
\text { Competências que } \\
\text { desenvolvem ao } \\
\text { cursar uma pós- } \\
\text { graduação, no que } \\
\text { se refere às } \\
\text { funções do } \\
\text { controller }\end{array}$} & $\mathrm{HC} 1$ & Responsável por conhecimentos de finanças \\
\hline & $\mathrm{HC} 2$ & Responsável por conhecimentos de orçamentos e avaliação econômica \\
\hline & HC3 & Responsável por conhecimentos de contabilidade geral \\
\hline & $\mathrm{HC} 4$ & Responsável por conhecimentos de tributária e fiscal \\
\hline & HC5 & Responsável por conhecimentos de custos \\
\hline & $\mathrm{HC} 6$ & Conhecimento dos princípios contábeis e legislação societária \\
\hline & $\mathrm{HC7}$ & Habilidades de liderança e trabalho em equipe \\
\hline & $\mathrm{HC} 8$ & Capacidade de influenciar os gerentes para a tomada de decisões \\
\hline & $\mathrm{HC9}$ & Planejamento Estratégico \\
\hline & HC10 & Mensuração de riscos organizacionais \\
\hline
\end{tabular}


Tabela 2 (continuação)

\begin{tabular}{|c|c|c|}
\hline Grupos & Cod. & Questões/variáveis \\
\hline \multirow{11}{*}{$\begin{array}{c}\text { Habilidades e } \\
\text { Competências que } \\
\text { desenvolvem ao } \\
\text { cursar uma pós- } \\
\text { graduação, no que } \\
\text { se refere às } \\
\text { funções do } \\
\text { controller }\end{array}$} & HC11 & Responsável pelos sistemas de informações gerenciais \\
\hline & HC12 & Conhecimentos de procedimentos de auditoria \\
\hline & $\mathrm{HC} 13$ & Consultoria \\
\hline & $\mathrm{HC} 14$ & Visão ampla e crítica das operações \\
\hline & $\mathrm{HC} 15$ & Proatividade \\
\hline & HC16 & $\begin{array}{l}\text { Desenvolvimento e implementação de controles internos, sistemas integrados, } \\
\text { entre outros }\end{array}$ \\
\hline & HC17 & Capacidade de resolver problemas e flexibilidade para mudanças \\
\hline & HC18 & Domínio de língua (s) estrangeira (s) \\
\hline & HC19 & Habilidades para trabalhar sob pressão \\
\hline & $\mathrm{HC2O}$ & Iniciativa \\
\hline & $\mathrm{HC21}$ & Capacidade para implantação de novas ideias e projetos \\
\hline
\end{tabular}

Nota. Fonte: Dados da pesquisa (2014).

Após o processo de coleta de dados, as respostas dos questionários foram tabuladas e analisadas de forma quantitativa, por meio de análise descritiva de frequências e estatística descritiva, teste de confiabilidade do instrumento de pesquisa utilizado (alfa de Cronbach), teste $\mathrm{t}$ de médias e ANOVA. Por fim, para relacionar as motivações com as habilidades $\mathrm{e}$ competências dos alunos de pós-graduação em Controladoria, utilizou-se o método estatístico de correlação canônica por meio do software estatístico StatGraphics ${ }^{\circledR}$.

\section{DESCRIÇÃO E ANÁLISE DOS RESULTADOS}

Esta seção apresenta a descrição e análise dos resultados do estudo. Inicialmente apresenta-se o perfil dos respondentes por meio de uma análise descritiva de frequências e estatística descritiva. Na sequência, o teste de confiabilidade de amostras independentes (alfa de Cronbach). Após, realizou-se o teste de médias a partir do teste t e ANOVA e, por fim, correlação canônica para analisar a relação entre as motivações e as habilidades e competências dos alunos. A partir da Tabela 3 apresenta-se o gênero dos respondentes.

Tabela 3

Gênero

\begin{tabular}{l|c|c}
\multicolumn{1}{c|}{ Gênero } & Frequência absoluta & Frequência relativa (\%) \\
\hline Feminino & 29 & $50 \%$ \\
\hline Masculino & 29 & $50 \%$ \\
\hline Total & $\mathbf{5 8}$ & $\mathbf{1 0 0 \%}$ \\
\hline
\end{tabular}

Nota. Fonte: Dados da pesquisa (2014).

Percebe-se na Tabela 3 que o gênero dos respondentes apresentou a mesma proporção, ou seja, metade são homens e a outra metade mulheres. Na Tabela 4 é apresentada a idade dos alunos da pós-graduação em Controladoria que responderam ao questionário.

Tabela 4

Idade

\begin{tabular}{c|c|c}
\hline Intervalo de Idade (anos) & Frequência absoluta & Frequência relativa (\%) \\
\hline $21-24$ & 28 & $49 \%$ \\
\hline $25-27$ & 11 & $19 \%$ \\
\hline $28-30$ & 3 & $5 \%$ \\
\hline $31-34$ & 10 & $17 \%$ \\
\hline $35-37$ & 3 & $5 \%$ \\
\hline $38-40$ & 2 & $3 \%$ \\
\hline Total & 1 & $2 \%$ \\
\hline
\end{tabular}

Nota. Fonte: Dados da pesquisa (2014). 
A partir da Tabela 4 verificou-se que a maioria dos respondentes possui idade entre 21 e 24 anos, representando $49 \%$ da amostra. Além disso, uma parcela significativa dos alunos tem entre 25 e 27 anos e 31 e 34 anos, o que perfaz 19\% e 17\%, respectivamente. Apenas um dos respondentes possui idade entre 41 e 44 anos. Na sequência, apresenta-se a Tabela 5, referente à área de formação.

Tabela 5

Área de formação (graduação)

\begin{tabular}{l|c|c}
\multicolumn{1}{c|}{ Área } & Frequência absoluta & Frequência relativa (\%) \\
\hline Administração & 7 & $12 \%$ \\
\hline Ciências Contábeis & 48 & $82 \%$ \\
\hline Outros & 3 & $6 \%$ \\
\hline Total & 58 & $\mathbf{1 0 0} \%$ \\
\hline
\end{tabular}

Nota. Fonte: Dados da pesquisa (2014).

Denota-se por meio da Tabela 5 que a área de formação (graduação) que prevaleceu entre os respondentes foi a de Ciências Contábeis, contemplando 48 respondentes, isto é, $82 \%$ da amostra, seguida de Administração com $12 \%$ e, por fim, outras áreas com $6 \%$. As outras áreas referem-se aos cursos de Economia, Logística e Sistemas de Informação. Na Tabela 6 é evidenciado há quanto tempo o aluno está formado na graduação.

Tabela 6

Tempo formado na graduação

\begin{tabular}{c|c|c}
\hline Intervalo do tempo (anos) & Frequência absoluta & Frequência relativa (\%) \\
\hline $0,5-3$ & 40 & $69 \%$ \\
\hline $4-5$ & 3 & $5 \%$ \\
\hline $6-7$ & 3 & $5 \%$ \\
\hline $8-9$ & 6 & $10 \%$ \\
\hline $10-12$ & 3 & $5 \%$ \\
\hline $13-14$ & 1 & $2 \%$ \\
\hline Total & 2 & $4 \%$ \\
\hline
\end{tabular}

Nota. Fonte: Dados da pesquisa (2014).

O tempo de formação dos alunos respondentes, conforme a Tabela 6, foi na sua maioria o período de 6 meses $(0,5$ anos) a 3 anos, visto que apresentou uma frequência absoluta de 40 respondentes, o que representa $69 \%$ da amostra. Os demais respondentes estão formados na graduação de 4 a 17 anos. A partir da Tabela 7 é demonstrada a área de atuação profissional dos respondentes.

Tabela 7

Área de atuação profissional

\begin{tabular}{l|c}
\multicolumn{1}{c|}{ Área } & Quantidade \\
\hline Administrativa & 9 \\
\hline Auditoria & 2 \\
\hline Contábil & 25 \\
\hline Controladoria & 6 \\
\hline Financeira & 12 \\
\hline Pública & 2 \\
\hline Outras & 2 \\
\hline
\end{tabular}

Nota. Fonte: Dados da pesquisa (2014). 
Segundo os dados apresentados na Tabela 7, a maioria dos respondentes atua na área contábil, ou seja, 25 alunos. Além disso, 12 alunos atuam na área financeira, 9 na área administrava e os demais nas áreas de auditoria, controladoria, pública e outras. A partir da Tabela 8 demonstra-se o nível da pós-graduação dos respondentes.

Tabela 8

Nível da pós-graduação

\begin{tabular}{l|c|c}
\multicolumn{1}{c|}{ Gênero } & Frequência absoluta & Frequência relativa (\%) \\
\hline Especialização & 43 & $74 \%$ \\
\hline MBA & 15 & $26 \%$ \\
\hline Total & $\mathbf{5 8}$ & $\mathbf{1 0 0 \%}$ \\
\hline
\end{tabular}

Nota. Fonte: Dados da pesquisa (2014).

Nota-se a partir da Tabela 8 que a maioria dos respondentes cursa a pós-graduação em nível de especialização, ou seja, $74 \%$. Dos 58 alunos, apenas 15 cursam MBA. Esse resultado difere do encontrado por Calijuri et al. (2005), visto que a maioria dos respondentes realizou a pós-graduação em MBA, ou seja, 19 controllers, e 14 cursaram especialização em Controladoria.

$\mathrm{Na}$ sequência, por meio da Tabela 9, apresenta-se a estatística descritiva, com o mínimo, máximo, média e desvio padrão no que se refere às variáveis do perfil dos respondentes sobre Gênero, Idade, Área de formação, Tempo de formação, Área de atuação e Nível da pós-graduação dos acadêmicos.

Tabela 9

Estatística Descritiva

\begin{tabular}{l|c|c|c|c}
\hline \multicolumn{1}{c|}{ Variáveis } & Mínimo & Máximo & Média & Desvio Padrão \\
\hline Gênero & 1 & 2 & 1,50 & 0,50 \\
\hline Idade & 21 & 44 & $\mathbf{2 6 , 8 3}$ & $\mathbf{5 , 3 6}$ \\
\hline Área de formação & 1 & 3 & 1,22 & 0,53 \\
\hline Tempo de formação & 0,5 & 17 & 3,82 & 4,15 \\
\hline Área de atuação & 1 & 8 & $\mathbf{4 , 2 6}$ & $\mathbf{1 , 7 8}$ \\
\hline Nível da pós & 1 & 2 & 1,26 & 0,44 \\
\hline
\end{tabular}

Nota. Fonte: Dados da pesquisa (2014).

De acordo com os dados da Tabela 9 nota-se que a variável Idade apresentou um valor mínimo de 21 e máximo de 44 . O respondente mais novo tinha 21 anos. O Tempo de formação dos alunos variou de meio ano para 17 anos. As demais variáveis, por terem sido codificadas, visto que são variáveis nominais, apresentaram o mínimo de 1 e o máximo de acordo com a codificação realizada.

Além disso, as variáveis Idade e Área de atuação profissional apresentaram valores entre os alunos da amostra, dispersos em relação a sua média, isto é, os valores estão distantes da média, o que pode ser notado a partir do desvio padrão de 5,36 e 1,78, respectivamente. As demais variáveis (Gênero, Área de formação, Tempo de formação e Nível da pós-graduação) tiveram um desvio padrão com valores baixos, entre 0,44 e 4,15, o que representa que estão próximos da média, sem dispersão.

Para verificar a confiabilidade do instrumento de pesquisa utilizado para o desenvolvimento deste estudo, realizou-se o teste de alfa de Cronbach, que apresentou um valor de 0,725 , ou seja, uma confiabilidade de $72 \%$ referente às motivações dos respondentes para buscar uma pós-graduação em Controladoria e 0,851 sobre as habilidades e competências, isto é, $85 \%$ de confiabilidade dos dados. Conforme Corrar, Paulo e Dias Filho (2009), quanto mais próximo de 1 estiver o alfa de Cronbach, melhor é a confiabilidade dos dados. Hair (1998) apresenta 0,7 como sendo o valor ideal, porém, pode-se aceitar 0,6 em pesquisas exploratórias.

Após, realizou-se o teste t de médias e ANOVA com o intuito de verificar se há diferença entre o perfil dos 58 respondentes e as motivações para buscar uma pós-graduação em controladoria, habilidades e competências que desenvolvem por meio da pós-graduação, no 
que se refere às funções do controller, e ainda, as contribuições da pós-graduação considerando a teoria e a prática. Diante disso, para as variáveis Gênero e Nível da pósgraduação aplicou-se o teste $t$ de médias, visto que são variáveis Dummy e para as demais variáveis, ou seja, Idade, Área de formação, Tempo que está formado na graduação e Área de atuação profissional, aplicou-se o teste ANOVA.

A partir desses testes estatísticos, constatou-se que não há diferença de médias entre o perfil dos respondentes com as motivações, habilidades e competências, bem como, de contribuições da pós-graduação em controladoria. Verifica-se, dessa forma, que o perfil dos respondentes não altera a resposta dos acadêmicos. A seguir, apresenta-se a correlação canônica do grupo das motivações com o grupo das habilidades e competências na Tabela 10.

Tabela 10

\section{Correlação canônica do grupo das motivações com o grupo das habilidades e competências}

\begin{tabular}{c|c|c|c|c|c|c}
\hline Número & Autovalor & $\begin{array}{c}\text { Correlação } \\
\text { Canônica }\end{array}$ & $\begin{array}{c}\text { Wilks } \\
\text { Lambda }\end{array}$ & Chi-Quadrado & D.F & P-Value \\
\hline 1 & 0,710956 & 0,843182 & 0,00335748 & 236,407 & 189 & 0,0109 \\
\hline 2 & 0,654893 & 0,809255 & 0,0116158 & 184,899 & 160 & 0,0865 \\
\hline 3 & 0,574864 & 0,758198 & 0,0336586 & 140,747 & 133 & 0,3061 \\
\hline 4 & 0,553073 & 0,743689 & 0,0791714 & 105,25 & 108 & 0,5570 \\
\hline 5 & 0,464146 & 0,681282 & 0,177146 & 71,8273 & 85 & 0,8452 \\
\hline 6 & 0,33155 & 0,575804 & 0,330587 & 45,9358 & 64 & 0,9570 \\
\hline 7 & 0,293768 & 0,542004 & 0,494557 & 29,2198 & 45 & 0,9670 \\
\hline 8 & 0,234536 & 0,484289 & 0,700276 & 14,7856 & 28 & 0,9806 \\
\hline 9 & 0,0851611 & 0,291824 & 0,914839 & 3,6938 & 13 & 0,9940 \\
\hline
\end{tabular}

Nota. Fonte: Dados da pesquisa (2014).

Conforme verificado na primeira coluna da Tabela 10, nove combinações lineares diferentes puderam ser calculadas por meio da correlação canônica, visto que este é o número do conjunto de variáveis do grupo das motivações para buscar uma pós-graduação em Controladoria, menor que o conjunto de variáveis do grupo habilidades e competências que desenvolvem por meio da pós-graduação, no que se refere às funções do controller.

Além disso, constata-se a partir da Tabela 8 que a primeira combinação linear entre o grupo das motivações e o grupo das habilidades e competências apresentou um coeficiente de correlação de 0,843182 e um $P$-Value significante a nível de $5 \%$, visto que foi de 0,0109 . Como um dos valores do $P$-Value é menor que 0,05 esse conjunto de variáveis apresentou uma correlação estatisticamente significativa ao nível de confiança de 95\%. De acordo com Hair, Babin, Money e Samuel (2005), representa uma força de associação alta, uma vez que ficou entre $+0,71$ e $+0,90$. Destaca-se também que nenhuma das demais combinações lineares apresentou $P$-Value significante ao nível de 5\%. Por meio da Tabela 11 apresentam-se os coeficientes para as variáveis canônicas do grupo das motivações com o grupo das habilidades e competências.

Tabela 11

Coeficientes para as variáveis canônicas do grupo das motivações com o grupo das habilidades e competências

\begin{tabular}{|c|c|c|c|c|c|c|c|c|c|c|}
\hline \multirow{2}{*}{ Número } & \multirow{2}{*}{ Variáveis } & \multicolumn{9}{|c|}{ Combinações lineares } \\
\hline & & 1 & 2 & 3 & 4 & 5 & 6 & 7 & 8 & 9 \\
\hline \multirow{9}{*}{$\begin{array}{l}\text { Motivações } \\
\text { para buscar } \\
\text { uma pós- } \\
\text { graduação em } \\
\text { Controladoria }\end{array}$} & M1 & $-0,3534$ & 0,2286 & 0,04639 & $-0,1980$ & 0,7436 & 0,08745 & 0,4750 & 0,1779 & 0,26529 \\
\hline & M2 & $-0,7427$ & 0,04420 & $-0,08891$ & $-0,00788$ & $-0,4799$ & $-0,2400$ & 0,3869 & $-0,9262$ & 0,07443 \\
\hline & M3 & 0,85090 & 0,45389 & $-0,3932$ & $-0,56158$ & 0,07773 & $-0,46728$ & 0,27589 & 0,50403 & $-0,5486$ \\
\hline & M4 & $-0,97768$ & $-1,08809$ & $-0,39020$ & $-0,08263$ & 0,18453 & 0,51768 & $-0,42186$ & 0,42842 & $-0,0131$ \\
\hline & M5 & 0,29724 & 1,1399 & 0,07269 & 0,05440 & 0,25808 & $-0,93668$ & $-0,34058$ & 0,17363 & 0,32669 \\
\hline & M6 & 0,24266 & 0,54856 & $-0,11525$ & 0,46951 & $-0,30194$ & 0,88175 & 0,08466 & 0,23771 & $-0,4013$ \\
\hline & M7 & $-0,42853$ & $-0,26020$ & 0,84034 & 0,18891 & 0,14345 & $-0,40662$ & $-0,14421$ & 0,09907 & $-0,3994$ \\
\hline & M8 & $-0,04676$ & $-0,37964$ & 0,35196 & $-0,36685$ & $-0,62112$ & 0,31767 & 0,14322 & 0,32469 & 0,63974 \\
\hline & M9 & 0,23855 & 0,31643 & 0,15088 & $-0,54648$ & 0,12222 & 0,34002 & $-0,46130$ & $-0,52483$ & $-0,2234$ \\
\hline
\end{tabular}


Tabela 11 (continuação)

\begin{tabular}{|c|c|c|c|c|c|c|c|c|c|c|}
\hline \multirow{2}{*}{ Número } & \multirow{2}{*}{ Variáveis } & \multicolumn{9}{|c|}{ Combinações lineares } \\
\hline & & 1 & 2 & 3 & 4 & 5 & 6 & 7 & 8 & 9 \\
\hline \multirow{21}{*}{$\begin{array}{c}\text { Habilidades e } \\
\text { competências } \\
\text { que } \\
\text { desenvolvem } \\
\text { por meio da } \\
\text { pós-graduação }\end{array}$} & $\mathrm{HC} 1$ & $-0,53485$ & 0,03655 & 0,23819 & $-0,20604$ & 0,50726 & 0,38599 & 0,13722 & $-0,21960$ & 0,38244 \\
\hline & $\mathrm{HC} 2$ & 0,12233 & 1,09162 & 0,09699 & 0,08466 & $-0,05043$ & 0,12513 & 0,17790 & $-0,00521$ & $-0,2036$ \\
\hline & $\mathrm{HC} 3$ & $-0,44939$ & $-0,49402$ & 0,30481 & 0,13528 & 0,50084 & 0,1623 & $-0,84300$ & $-0,55839$ & $-0,3284$ \\
\hline & $\mathrm{HC} 4$ & 0,13236 & $-0,47355$ & $-0,11561$ & $-0,78786$ & $-0,23231$ & $-0,69142$ & 0,58915 & 0,05470 & $-0,1180$ \\
\hline & HC5 & $-0,69883$ & 0,21405 & 0,01687 & 0,79321 & $-0,28474$ & 0,64334 & $-0,35863$ & 0,05664 & 0,14125 \\
\hline & $\mathrm{HC} 6$ & 0,06505 & 0,08855 & 0,28972 & $-0,11836$ & $-0,88036$ & $-0,50895$ & 0,26646 & 0,51725 & 0,00371 \\
\hline & $\mathrm{HC} 7$ & $-0,44189$ & $-0,38671$ & 0,10624 & 0,08875 & $-0,16974$ & $-0,29761$ & $-0,31085$ & $-0,47135$ & 0,23353 \\
\hline & HC8 & 0,38345 & 0,67326 & 0,37042 & 0,21020 & 0,01008 & 1,10791 & 0,31831 & $-0,43436$ & $-0,4397$ \\
\hline & $\mathrm{HC} 9$ & 0,33659 & $-0,15974$ & 0,88738 & $-0,61372$ & 0,79061 & $-0,02092$ & $-0,17860$ & 0,58611 & 0,28283 \\
\hline & $\mathrm{HC} 10$ & $-0,03065$ & 0,11235 & $-0,80140$ & 0,49697 & 0,34899 & $-0,45968$ & $-0,24923$ & 0,33462 & $-0,1816$ \\
\hline & HC11 & 0,00461 & $-0,32815$ & $-0,52308$ & $-0,40148$ & $-0,48141$ & $-0,42019$ & $-0,27843$ & $-0,20392$ & 0,30612 \\
\hline & $\mathrm{HC} 12$ & $-0,07203$ & $-0,07445$ & 0,33346 & 0,56218 & 0,15735 & $-0,12585$ & 0,02705 & $-0,29402$ & 0,29535 \\
\hline & $\mathrm{HC} 13$ & 0,21445 & $-0,31876$ & $-0,31129$ & $-0,10471$ & 0,50746 & 0,48078 & 0,25056 & $-0,20291$ & 0,02468 \\
\hline & 4 & 0,42004 & $-0,32981$ & $-0,06615$ & 0,01072 & 0,48116 & $-0,29272$ & 0,50622 & 0,01612 & $-0,3348$ \\
\hline & 15 & $-1,31573$ & $-0,30200$ & $-0,21841$ & $-0,10451$ & 0,04298 & $-0,40888$ & $-0,03986$ & 0,24504 & 0,27096 \\
\hline & $\mathrm{HC} 16$ & $-0,34396$ & 0,61572 & 0,68681 & 0,38759 & $-0,13178$ & 0,33450 & 0,18264 & $-0,31780$ & $-0,0225$ \\
\hline & HC17 & 0,34169 & 0,22594 & $-0,28223$ & 0,27431 & $-0,42221$ & 0,02001 & $-0,31745$ & 0,24404 & 0,38564 \\
\hline & HC18 & 0,16145 & $-0,52635$ & $-0,11429$ & $-0,27947$ & 0,18779 & 0,47915 & $-0,1651$ & 0,56490 & 0,29540 \\
\hline & & 0,35533 & 0,21288 & 0,02641 & $-0,20148$ & 0,14430 & $-0,39590$ & $-0,31980$ & $-0,32539$ & $-0,0704$ \\
\hline & 20 & $-0,08159$ & $-0,39952$ & $-0,01784$ & 0,25754 & $-0,22205$ & $-0,26192$ & 0,41782 & $-0,37560$ & $-0,0798$ \\
\hline & $\mathrm{HC} 21$ & 0,65077 & 0,08433 & $-0,44299$ & $-0,84032$ & $-0,28633$ & $-0,00029$ & 0,09173 & 0,39927 & $-0,6235$ \\
\hline
\end{tabular}

Nota. Fonte: Dados da pesquisa (2014).

A partir da Tabela 11 obtiveram-se os resultados sobre a relação entre as motivações e as habilidades e competências. Foram analisadas apenas as variáveis que apresentaram força de associação acima de moderada, conforme Hair et al. (2005), ou seja, acima de +0,41.

A única variável do grupo motivação que se apresentou com força de associação acima de moderada foi a variável de perspectiva de aumento salarial (M3). Teve um valor de 0,85090 e a força de associação alta, visto que a força de associação alta para Hair et al. (2005) vai de $+0,71$ a $+0,90$. Essa variável apresenta combinação linear com duas variáveis de habilidades e competências, isto é, visão ampla e crítica das operações (HC14) e capacidade para implantação de novas ideias e projetos (HC21).

Essa combinação indica que quanto maior é a perspectiva de aumento salarial, maior será a visão ampla e crítica das operações e a capacidade para implantação de novas ideias e projetos. Nesse sentido, o estudo desenvolvido por Martin (2002) revelou que o controller necessita ter capacidade de entender profundamente a empresa e o ramo de negócios em que atua.

Entretanto, de acordo com o resultado obtido, apresentado na Tabela 8, quanto maior for à perspectiva de aumento salarial, menor será a responsabilidade por conhecimentos de finanças (HC1), conhecimentos de contabilidade geral (HC3), conhecimentos de custos (HC5), habilidades de liderança e trabalho em equipe (HC7) e pro atividade (HC15).

Esses resultados demonstraram que a motivação perspectiva de aumento salarial está relacionada com algumas das habilidades e competências desenvolvidas por meio da pósgraduação, no que se refere às funções do controller.

Além disso, verificou-se, a partir da Tabela 8, que, quanto menor forem as motivações: perspectiva de melhorias na carreira (M2) e a satisfação profissional (M4), maiores serão as habilidades e competências: visão ampla e crítica das operações (HC14) e capacidade para implantação de novas ideias e projetos (HC21). Contudo, quanto menor forem as motivações: perspectiva de melhorias na carreira e a satisfação profissional, menores serão as responsabilidades por conhecimentos de finanças $(\mathrm{HC} 1)$, responsabilidades por conhecimentos de contabilidade geral (HC3), responsabilidades por conhecimentos de custos (HC5), habilidades de liderança e trabalho em equipe ( $\mathrm{HC} 7)$, proatividade $(\mathrm{HC} 15)$, ou seja, essas cinco habilidades e competências.

A partir desses resultados encontrados neste estudo, nota-se que os resultados do estudo de Siqueira e Soltelinho (2001) apontaram que o mercado busca profissionais que 
sejam habilitados a trabalhar sob pressão e em equipe. Na presente pesquisa essa habilidade e competência apresentou força de associação negativa, diferente, no entanto, do resultado encontrado por esses autores.

Além disso, Siqueira e Soltelinho (2001) ressaltam que o controller é um profissional estratégico para fornecer uma visão crítica para a administração da empresa.

Contudo, o resultado do presente estudo vai ao encontro do de Calijuri et al. (2005) e Dal Vesco et al. (2014), que também verificaram que a habilidade mais importante para o desempenho do trabalho de um controller é a capacidade para implantação de novas ideias e projetos (Dal Vesco et al., 2014). Porém, vai ao encontro de outras habilidades e competências, visto que apontaram a liderança (Calijuri et al., 2005, Santos et al., 2005, Machado et al., 2010, Ferrari et al., 2013, Gomes et al., 2014 e Dal Vesco et al., 2014), o conhecimento de finanças (Dal Vesco et al., 2014) e a proatividade (Gomes et al., 2014, Ferrari et al., 2013), como sendo importantes. Nesta pesquisa apresentaram associação negativa com as motivações dos alunos de pós-graduação em controladoria.

Além disso, os resultados contradizem com alguns dos encontrados por Amaral e Rodrigues (2006). Na visão dos professores, o controller possui a função de controle financeiro, contabilidade geral e de custos (Santos et al., 2005, Dal Vesco et al., 2014). Entretanto, em relação à visão dos profissionais, os resultados vão ao seu encontro, uma vez que destacam que uma das principais funções do controller é que o funcionário deve fornecer uma visão crítica das operações (Ferrari et al., 2013, Dal Vesco et al., 2014).

Ainda, os resultados do estudo de Araújo et al. (2014) diferem da presente pesquisa, visto que esses autores revelaram que em relação às habilidades e competências mais desenvolvidas se destacam as relacionadas aos conhecimentos em finanças e contabilidade geral.

Todas as habilidades e competências que esses autores destacaram como importantes para o controller apresentaram força de associação negativa com as motivações analisadas no presente estudo, de acordo com as respostas dos alunos. Em relação às motivações dos alunos não se localizou qualquer estudo que tenha encontrado a relação das motivações que apresentaram força de associação tanto positiva quanto negativa com tais habilidades e competências.

\section{CONCLUSÕES}

Este estudo analisou a relação entre as motivações e as habilidades e competências do controller na percepção de alunos de pós-graduação em controladoria a partir de uma pesquisa descritiva, de levantamento e quantitativa. A amostra do estudo compreendeu os 58 alunos que cursam pós-graduação em controladoria no Estado de Santa Catarina e que responderam ao questionário.

Para a descrição e análise dos dados utilizou-se análise descritiva de frequências e estatística descritiva, teste de confiabilidade do instrumento de pesquisa utilizado (alfa de Cronbach), teste t de médias e ANOVA e, ainda, correlação canônica para analisar a relação entre as motivações e as habilidades e competências.

Em relação ao perfil dos respondentes, os resultados deste estudo revelaram que a metade dos respondentes eram homens e a outra metade mulheres. A maioria dos respondentes possui idade entre 21 e 24 anos. O tempo de formação dos alunos respondentes foi na sua maioria o período de seis meses a três anos. A área de formação (graduação) que prevaleceu foi a de Ciências Contábeis. A maioria dos respondentes atua na área contábil e cursa a pós-graduação em nível de especialização.

Diante dos resultados encontrados, pode-se concluir que quanto maior é a perspectiva de aumento salarial, maior será a visão ampla e crítica das operações e a capacidade para implantação de novas ideias e projetos e menor será a responsabilidade por conhecimentos de finanças, conhecimentos de contabilidade geral, conhecimentos de custos, habilidades de liderança e trabalho em equipe e proatividade.

Entretanto, quanto menor forem as motivações: perspectiva de melhorias na carreira e a satisfação profissional, maiores serão as habilidades e competências, visão ampla e crítica das 
operações e capacidade para implantação de novas ideias e projetos e menores serão as responsabilidades por conhecimentos de finanças, responsabilidades por conhecimentos de contabilidade geral, responsabilidades por conhecimentos de custos, habilidades de liderança e trabalho em equipe e proatividade.

Este estudo contribui para que as IES analisadas verifiquem as motivações dos alunos para buscar uma pós-graduação em controladoria e, por meio dessas, ajustem seus cursos, pois a motivação relacionada à perspectiva de aumento salarial foi a única que apresentou força de associação positiva alta com as habilidades e competências visão ampla e crítica das operações e capacidade de implementar novas ideias e projetos, no que se refere às funções do controller.

Araújo et al. (2014) ressaltam que um curso de pós-graduação pode adicionar valor aos alunos, tornando-os mais preparados para enfrentar o mercado de trabalho. Entretanto, vale destacar que é preciso estar atento às motivações e às habilidades e competências dos alunos.

As limitações deste estudo consistem na impossibilidade da generalização dos resultados, visto que a população foi intencional e não probabilística, escolhida devido à facilidade de acesso aos respondentes. Dessa forma, os questionários não foram encaminhados a todas as IES de Santa Catarina. Além disso, outra limitação é obter todos os questionários devidamente respondidos visto que de 278 questionários encaminhados, apenas 58 retornaram respondidos. Sugere-se, para trabalhos futuros, a ampliação da população para todas as IES de Santa Catarina e/ou Brasil, visto que uma nova amostra possibilitará a utilização deste estudo para fins de comparabilidade dos resultados.

\section{REFERÊNCIAS}

Amaral, M. S. do, \& Rodrigues, M. S, (2006). O ensino da disciplina de controladoria nos programas de pós-graduação em nível de especialização em ciências contábeis e o profissional controller atuante no mercado de trabalho. Revista Enfoque: Reflexão Contábil, 25(3), 17-28.

Araújo, J. G. R., Callado, A. L. C., \& Cavalcanti, B. S. B. (2014). Habilidades e competências do controller: um estudo com alunos de cursos de pós-graduação em controladoria. Revista Catarinense da Ciência Contábil, 13(38), 52-64.

Araújo, R. H. M., Souto, S. D. A. S., \& de Azevedo, T. K. G. N. (2016). Características da Atuação Funcional do Controller. Uma Investigação Sobre o Nível de Utilização de Competências Individuais em Entidades do Setor Público. RAGC - Revista de Auditoria Governança e Contabilidade, 4(11), 10-26.

Baruch, Y., \& Leeming, A. (2001). The added value of MBA studies-graduates' perceptions. Personnel Review, 30(5), 589-602.

Bencová, M., \& Kal'avská, A. (2009). Importance of the Controllership for the Company Performance-Software Company Experience. E+M Ekonomie a Management, (2), 76.

Borges, T. N., Parisi, C., \& Gil, A. D. L. (2005). O Controller como gestor da Tecnologia da Informação: realidade ou ficção?. Revista de Administração Contemporânea, 9(4), 119140.

Borinelli, M. L. (2006) Estrutura Conceitual Básica de Controladoria: Sistematização a Luz da Teoria e da Práxis. 2006. 341 f. Tese de Doutorado. Departamento de Ciências Contábeis, FEA-USP, São Paulo, SP, Brasil.

Calijuri, M. S. S., Santos, N. M. B. F., \& Santos, R. F. dos. (2005). Perfil do controller no contexto organizacional atual brasileiro. Anais Congresso Brasileiro de Custos, Florianópolis, SC, Brasil, 12.

Corrar, L. J., Paulo, E., \& Dias Filho, J. M. (2009). Análise multivariada para os cursos de Administração, Ciências Contábeis e Economia. São Paulo: Atlas. 
Dal Vesco, D. G., Daniel, M. M., \& Tarifa, M. R. (2014). Estudo do perfil, conhecimento, papel e atuação do controller em cooperativas. Revista de Finanças Aplicadas, 2(1), 1-31.

Duque, C. (2011). O perfil profissional do Controller e as funções de Controladoria: um estudo da atual necessidade do mercado de trabalho. 105 f. 2011. Dissertação (Mestrado) Universidade Federal de Pernambuco, Pernambuco, Brasil.

Ferrari, M. J., Cunha, L. C., Lunkes, R. J., \& Borgert, A. (2013). O perfil do controller sob a ótica do mercado de trabalho brasileiro. Revista de Informação Contábil, 7(3), 25-50.

Frezatti, F., \& Kassai, S. (2003). Estudo do impacto de um curso MBA em controladoria na evolução de seus egressos. Revista Contabilidade \& Finanças, 14(SPE), 54-65.

Gomes, C. V., Souza, P. de, \& Lunkes, R. J. (2014). O perfil do profissional da controladoria solicitado por empresas brasileiras. Revista de Globalización, Competitividad y Gobernabilidad, 8(1), 34-50, 2014.

Granlund, M., \& Taipaleenmäki, J. (2005). Management control and controllership in new economy firms-a life cycle perspective. Management Accounting Research, 16(1), 21-57.

Guimarães, I. C., Parisi, C., Pereira, A. C., \& Weffort, E. F. J. (2009). A Importância da Controladoria na Gestão de Riscos das Empresas Não-Financeiras: um estudo da percepção de gestores de riscos e controllers. Revista Brasileira de Gestão de Negócios, 11(32), 260-275.

Hair, J. F., Jr. (1998). Multivariate data analysis with readings (4a ed.). Uper Saddle River: Prentice Hall, 1998.

Hair, J. F., Jr., Babin, B., Money, A. H., \& Samuel, P. (2005). Fundamentos de Métodos de Pesquisa em Administração. Porto Alegre: Bookman.

Lunkes, R. J., Gasparetto, V., \& Schnorrenberger, D. (2010). Um estudo sobre as funções da controladoria. Revista de Contabilidade e Organizações, 4(10), 106-126.

Lunkes, R. J., Machada, A. de O., Rosa, F. S. da, \& Telles, J. (2011). Funções da controladoria: Um estudo nas 100 maiores empresas do Estado de Santa Catarina. Análise Psicológica, 29(2), 345-361.

Lunkes, R. J., Schnorrenberger, D., Gasparetto, V., \& Vicente, E. F. R. (2009). Considerações sobre as funções da controladoria nos Estados Unidos, Alemanha e Brasil. Revista Universo Contábil, 5(4), 63-75.

Lunkes, R. J., Schnorrenberger, D., \& da Rosa, F. S. (2013). Funções da Controladoria: uma análise no cenário brasileiro. Revista Brasileira de Gestão de Negócios, 15(47), 283-299.

Machado, A. D. O., Lunkes, R. J., Petri, S. M., \& Rosa, F. S. D. (2010). Competências do controller. um estudo nas 100 maiores empresas de Santa Catarina. Pensar Contábil, 12(47), 26-34.

Martin, N. C. (2002). Da contabilidade à controladoria: a evolução necessária. Revista Contabilidade \& Finanças, 13(28), 7-28.

Oro, I. M., Beuren, I. M., \& Carpes, A. M. S. da. (2013). Competências e habilidades exigidas do controller e a proposição para sua formação acadêmica. Contabilidade Vista \& Revista, 24(1), 15-36.

Pletsch, C. S., Silva, A. da, \& Lavarda, C. E. F. (2016). Conteúdos da disciplina de controladoria e as funções do controller no mercado de trabalho. Revista Pretexto, 17(1), 118-133.

Richartz, F., Krüger, L. M., Lunkes, R. J., \& Borgert, A. (2012). Análise curricular em controladoria e as funções do Controller. Revista Iberoamericana de Contabilidad de Gestión, 9(19), 25-39. 
Santos, R. V., Castellano, A. C. F., Bonacim, C. A. G., \& Silva, L. R. V. (2005). O papel do controller em empresas de grande porte. Anais de Congresso Internacional de Custos Florianópolis, SC, Brasil, 10.

Simãozinho, S. D. M. (2012). Gestão do conhecimento na área de controladoria: um estudo de caso em modelo de estrutura descentralizada. Dissertação (Mestrado) - Universidade Presbiteriana Mackenzie, São Paulo.

Siqueira, J. R. M. de, \& Soltelinho, W. (2001). O profissional de controladoria no mercado brasileiro: do surgimento da profissão aos dias atuais. Revista Contabilidade \& Finanças, 12(27), 66-77.

Weber, J. (2011). The development of controller tasks: explaining the nature of controllership and its changes. Journal of Management Control, 22(1), 25-46.

Weissenberger, B. E., \& Angelkort, H. (2011). Integration of financial and management accounting systems: the mediating influence of a consistent financial language on controllership effectiveness. Management Accounting Research, 22(3), 160-180. 